RTIGOS 


\section{Cinema e Representações da Mobilidade Africana}

\section{Cinema and Representations of African Mobility}

\section{Astréia Soares Batista}

Doutora em Ciências Humanas - Sociologia pela Universidade Federal do Rio de Janeiro (2006), Mestre em Sociologia da Cultura pela Universidade Federal de Minas Gerais (1993) e graduada em Ciências Sociais pela Universidade Federal de Minas Gerais (1981). Desde 1991 é professora Titular I da Universidade FUMEC/MG. ID ORCID: 0000-0001-5072-1453. Colaboração: Pesquisa bibliográfica, pesquisa empírica, análise de dados e redação.

\section{Luiz Henrique Barbosa}

Doutor em Literaturas de Língua Portuguesa pela Pontifícia Universidade Católica de Minas Gerais (2010), Mestre em Estudos Literários pela Universidade Federal de Minas Gerais (1995) e graduado em Letras (Língua Portuguesa) pela Universidade Federal de Minas Gerais (1989). Desde 2000 é professor Assistente da Universidade Fumec/MG. ID ORCID: 0000-0001-7447-4901. Colaboração: Pesquisa bibliográfica, pesquisa empírica, análise de dados e redação.

\section{Maria Cristina Leite Peixoto}

Doutora em Ciências Humanas - Sociologia pela Universidade Federal do Rio de Janeiro (2006), Mestre em Sociologia pela Universidade Federal de Minas Gerais (1993) e graduada em Ciências Sociais pela Universidade Federal de Minas Gerais (1987). ID ORCID: 0000-0002-7208-4755. Colaboração: Pesquisa bibliográfica, pesquisa empírica, análise de dados e redação.

\section{Resumo}

Neste artigo discutimos as representações que o cinema de ficção faz da mobilidade de povos africanos, a partir da análise dos filmes Casa de Lava (1994) de Pedro Costa, Nha Fala (2002), de Flora Gomes, e Virgem Margarida (2012), de Licínio Azevedo. Buscamos relatar as trajetórias dos personagens centrais desses filmes ao deixarem seus locais de origem e serem expostos a culturas e costumes distintos daqueles que compartilham com seu grupo e os impactos de tais deslocamentos na formação de identidade desses sujeitos. A análise aborda as motivações dos personagens para se afastarem de seus universos familiares, bem como seus encontros e estranhamentos. Destaca, no contexto das migrações, as relações entre tradição e modernidade, entre o sujeito deslocado e a noção de casa e o papel do Estado como agente de deslocamentos, migrações e diásporas.

Palavras-chave: Cinema, África, Mobilidade Humana, Representações, Identidade.

\section{Abstract}

In this article we discuss the representations in fictional films about African people mobility's, analyzing the films Casa de Lava (1994), directed by Pedro Costa, Nha Fala (2002), directed by 
Flora Gomes, and Virgem Margarida (2012), directed by Licínio Azevedo. We seek to report the trajectories of the central characters of these films when they leave their original places and are being exposed to different cultures and customs of those who they used to share with your original groups and the impact of these displacement in the their conception of identity. The analysis discusses the motivations of the characters to move from their familiar universes, their meetings and strange feelings and highlights in the context of migration the relationship between tradition and modernity, between the shifted person and the idea of home and the role of the State as an agent of displacements, migrations and diasporas.

Keywords: Cinema, Africa, Human Mobility, Representation, Identity.

\section{INTRODUÇÃO}

O foco central deste artigo são as representações que o cinema de ficção produz sobre diferentes formas de mobilidade dos povos africanos, em épocas variadas e levadas por diversas motivações. Essa discussão se volta para a África de língua portuguesa, o que nos direcionou à análise dos filmes Casa de Lava (Portugal, França e Alemanha, 1994), de Pedro Costa, Nha Fala (Portugal, França e Luxemburgo, 2002), de Flora Gomes, e Virgem Margarida (França, Portugal e Moçambique, 2012), de Licínio Azevedo. Nas narrativas originais desses filmes predomina o português, com presença das línguas crioulas de origem portuguesa - crioulo do Cabo Verde em Casa de Lava e crioulo guineense em Nha Fala. São aspectos referenciados na história colonial de Cabo Verde, na Guiné-Bissau contemporânea e no Moçambique pós-descolonização, respectivamente.

Os estudos africanos no Brasil, apesar do crescimento importante nos últimos anos, ainda carecem de incentivos para adensar seu conhecimento. Esta é, certamente, a situação do cinema produzido por cineastas africanos, entre eles, os de língua portuguesa. O maior volume de estudos acadêmicos se dá por pesquisadores de língua inglesa em países africanos de mesma língua, o que reforça a opção, neste artigo, por estudar filmes feitos em países de língua portuguesa. Além do fato de que em muitos países africanos as línguas oficiais são o inglês e o francês, o que acentua o desconhecimento sobre a produção artístico-cultural dessas localidades no Brasil, a falta de maior atenção à filmografia africana deve-se, também, à insistência da perspectiva eurocêntrica e preconceituosa em não reconhecer a participação do/a africano/a na 
construção do cinema. A leitura das obras de grandes escritores africanos e o acesso a sua produção cinematográfica em língua portuguesa, por exemplo, podem significar uma contribuição no sentido de diminuir essa defasagem.

A nacionalidade dos diretores não foi um dado relevante na seleção dos filmes, já que apenas o guineense Flora Gomes é nascido na África. Pedro Costa, português por origem, tem uma filmografia diretamente relacionada aos objetivos deste artigo, por tratar principalmente do tema dos cabo-verdianos deslocados, e Licínio Azevedo, brasileiro, vive em Moçambique e é considerado "pai do cinema moçambicano".

O objetivo do artigo - discutir as representações que o cinema de ficção faz da mobilidade de povos africanos, a partir da análise dos filmes Casa de Lava (1994), de Pedro Costa, Nha Fala (2002), de Flora Gomes, e Virgem Margarida (2012), de Licínio Azevedo -, teve o suporte de conceitos fundamentais para a reflexão proposta, os quais foram seguidos dos pressupostos teóricos que a nortearam e dos procedimentos de análise ${ }^{1}$.

\section{REPRESENTAÇÕES SOCIAIS E MOBILIDADE HUMANA}

As representações sociais (MOSCOVIC, 1978) são modalidades de conhecimento prático voltadas para a comunicação e a compreensão do contexto social, material e ideativo em que vivem os homens. São, pois, formas de conhecimento que se manifestam como imagens, conceitos, categorias e teorias, elaboradas e compartilhadas socialmente, capazes de auxiliar na construção de uma realidade comum, que possibilita a comunicação. Contudo, são fenômenos sociais que, mesmo acionados a partir do seu conteúdo cognitivo, devem ser entendidos com base em seu contexto de produção.

As representações midiáticas cinematográficas foram percebidas aqui como maneiras de interpretar e pensar a realidade cotidiana que resultam em conteúdos públicos. Na sociedade contemporânea, são práticas comunicacionais e discursivas fundamentais que auxiliam os receptores de produtos

\footnotetext{
Embora haja vasta literatura a respeito das migrações e representações, optou-se pelas referências clássicas de análise desses temas (FERRO, 2010; MOSCOVIC, 1978), bem como pela perspectiva dos Estudos Culturais para pensar sobre a mobilidade humana. Isso ocorreu em função das dimensões deste artigo e do pertencimento dos seus autores a um programa de mestrado na área.
} 
das mídias a tomar posição em relação a situações, temas e acontecimentos que lhes dizem respeito. As representações difundidas pelo cinema podem formar um sistema de referências que, compartilhadas pelos membros de um grupo, possibilitam o aparecimento de uma visão mais ou menos consensual da realidade.

Quanto às formas de mobilidade humana - diásporas, migrações e nomadismos impulsionados por diferentes motivações -, estas são fenômenos inseridos na dinâmica social e que se intensificaram nas sociedades contemporâneas, relacionados a elementos econômicos, sociais, culturais e até mesmo afetivos. Tradicionalmente são vistas como investidas de mobilidade espacial entre países e regiões por um longo período de tempo. Entretanto, afetada pelo enfraquecimento da noção de fronteira e pela relativização do tempo, ambos decorrentes da globalização, assim como pelo desenvolvimento tecnológico que intensificou o trânsito humano, a mobilidade global tem sido ressignificada. As formas de mobilidade vigentes constituem um movimento de desterritorialização espacial e subjetiva, pelo qual o imigrante tem sua ligação com seu lugar de origem e com sua constituição identitária desestabilizada em função da experiência com a alteridade. Produzem impactos socioculturais relevantes, tanto no nível macro - economia, papéis de gênero, indicadores populacionais, culturas - quanto no nível micro, com a criação de sujeitos desterritorializados, deslocados e, muitas vezes, desenraizados. Estes, pela experiência adquirida nos deslocamentos, com a exposição a outras práticas culturais, o estabelecimento de relações interculturais e o cruzamento de trajetórias e identidades diversas, tornam-se portadores de novos valores e visões de mundo que os levam a reinventar culturas, tradições e a si mesmos.

Entendemos o caso africano como emblemático desse fenômeno, conforme nos lembra Venâncio (2009) ao observar que as migrações pela África são anteriores à chegada do europeu e aos processos de colonização, quando os deslocamentos eram motivados basicamente por conflitos étnicos, na busca por melhores condições ambientais, como acesso à água, a pastagens ou fuga das secas. Estes ocasionaram, ainda, grande parte dos movimentos migratórios durante a colonização e foram, em geral, regulados por programas estabelecidos pelo poder colonizador. A crescente urbanização dos países africanos, a partir dos anos 1970, aumentou consideravelmente os fluxos migratórios e, ao lado dos conflitos étnicos, surgiram outras causas relevantes, 
como as guerras e embates civis, os conflitos religiosos, os desastres naturais e a deterioração ambiental, além da pobreza e da descrença da capacidade estatal de regulamentar a vida econômica, civil e militar.

No período pós-colonial, a diáspora africana passa a ter como destino principal os países considerados mais desenvolvidos economicamente, em especial as ex-metrópoles coloniais, fomentada pela possibilidade de superação dos problemas econômicos e sociais que afligem a maioria dos países do continente. É provável que a opção de seguir em direção a uma ex-metrópole colonial se dê pela suposição de que ali é viável encontrar uma afinidade cultural e linguística e, muitas vezes, um núcleo familiar que já migrou anteriormente. Entretanto, essa expectativa de laços nem sempre se concretiza, e os migrantes quase sempre não são inseridos em pé de igualdade econômica, social ou cultural no país que os recebe. São marcados pela condição concreta de serem minorias e de estarem desterritorializados.

Segundo Venâncio (2009),

A falta de mecanismos e organismos apropriados à defesa dos seus direitos, confirmando a sua "invisibilidade social" (onde, em parte, radica a sua classificação enquanto minoria), leva-os a procurar apoio junto dos seus conterrâneos, com quem acabam por desenvolver, porque, na verdade, se sentem discriminados pela sociedade global, uma solidariedade de exclusão (VENÂNCIO, 2009,p.142).

Ainda que o país que receba o migrante estabeleça políticas de integração multicultural, estas não têm sido suficientes para eliminar manifestações de diferentes formas de preconceito e de exclusão, principalmente no campo do trabalho.

A mobilidade humana pode ser interpretada, como aponta Bauman (1998), como uma das condições para ser moderno, sinônimo de estar sempre em movimento. Isso não é propriamente uma escolha. No mundo globalizado em que vivemos, todos os habitantes são nômades, mas nômades à procura de um local para se fixar. Esse esforço tem sido inglório, já que "depois de cada curva surgem novas curvas, com novas frustrações e novas esperanças ainda não destroçadas” (BAUMAN, 1998, p.92).

Entretanto, de acordo com Appiah (2010), há uma especificidade relativa ao continente africano no que se refere ao mal-estar contemporâneo 
analisado por Bauman. Enquanto o europeu se pergunta por sua identidade individual, ou seja, quem ele ou ela é, o africano se pergunta "quem somos nós”. O problema não é individual, mas coletivo, não é somente uma busca de compreensão do eu, mas do "nós".

A história do continente africano provavelmente justifica esta especificidade devido a fatores que não são frequentemente encontrados fora da África. Appiah (2010) enumera:

Uma história colonial recente, uma multiplicidade de variadas tradições locais subnacionais, uma língua estrangeira cuja cultura metropolitana tradicionalmente definiu os "nativos" como inferiores, por sua raça e uma cultura literária ainda basicamente em processo de formação (APPIAH, 2010, p.116).

O mesmo autor aponta para a questão de caráter epistemológico que coloca em discussão a existência de uma vida cultural, política e intelectual africana que pudesse ser presumida. O que existe, ele conclui, é apenas "um sem-número de tradições, com suas relações complexas - e, com igual frequência, sua falta de qualquer relação - umas com as outras" (APPIAH, 2010, p. 120).

Além disso, o acadêmico nos alerta para o fato de que as culturas africanas não são "um livro aberto umas para as outras", o que impede generalizações acerca da existência concreta de um dado mundo africano ou de um pan-africanismo, como pretenderam as teses nacionalistas que emergiram na África pós-colonial, bem como as construções externas, elaboradas pela perspectiva ocidental. Appiah (2010, p. 122) afirma que "o que os africanos têm em comum é, fundamentalmente, o fato de o racismo europeu não ter sabido levá-los a sério, de o imperialismo europeu os haver explorado”.

Da mesma forma com que este autor se refere criticamente a uma "cultura africana", a ideia de um cinema africano padece do mesmo problema. Tal abordagem implicaria um processo consensual de construção de valores comuns às suas múltiplas etnias, o que parece ser um ideal não concretizado, embora presente nas teses nacionalistas pós-coloniais. Entretanto, pode-se identificar que há um interesse do cinema produzido na África de evidenciar uma outra relação de identidade, "para além das fronteiras artificiais e fictí- 
cias herdadas da colonização e que definem os contornos dos estados modernos africanos" (BAMBA, 2010, p.271).

De acordo com Bamba (2010), diante de uma realidade atual desoladora e fortemente dividida, esse cinema tem recorrido aos seus mitos fundadores, às grandes epopeias oralmente transmitidas e à literatura para criar uma estratégia de superação e revanche ao colonialismo. Isso não significa, porém, que filmes africanos se limitem a uma volta ao passado, às tradições orais e costumes locais; eles chamam atenção para questões do presente, no sentido de ultrapassar as imagens culturais estereotipadas. O cinema feito na África segue na busca por representações sobre o continente que ocorrem, muitas vezes, num quadro de instabilidade social.

A produção cinematográfica tem contribuído para aumentar a visibilidade da diversidade cultural e dos processos que acompanham a dinâmica da globalização, dentre os quais a mobilidade humana, objeto deste artigo, e seus impactos na sociedade e nas culturas tradicionais. Pode-se dizer que o cinema vem se afirmando como uma mídia portadora de significação e um meio privilegiado de comunicação e representação para comunidades diversas.

Diretores que trabalham com a temática de África irão nos apresentar olhares simbólicos sobre fatos que correspondem a um mundo tido como real, carregados de significado e impregnados da sua percepção. Ou seja, não são produções imparciais e neutras. Na análise de Ferro (2010), esta seria uma característica inerente ao fazer cinematográfico, de modo amplo. Para ele, o filme teria o papel de ajudar na "construção de uma contra-história" que se torna liberada da história oficial e de arquivos escritos unicamente a partir da memória conservada pelas instituições formais.

Esta perspectiva discutida pelo historiador torna-se mais complexa quando falamos dos arquivos restritos, registros incompletos e memória pouco resguardada da arte e da cultura de muitos países, principalmente dos territórios africanos, tradicionalmente alijados de grande parte dos processos produtivos das artes. Segundo relatório da UNESCO (2009), apesar do crescimento das exportações de produtos relacionados com a comunicação, provenientes de países recentemente industrializados, do surgimento de novos centros midiáticos regionais e da expansão das redes de informação, criando inéditas possibilidades de expressão de vozes alternativas, as produções afri- 
canas do setor audiovisual encontram condições limitadas para explorar suas competências criativas em proveito do desenvolvimento desse setor.

Por exemplo, a participação da África no comércio mundial de produ-
tos criativos continua a ser marginal - menos de $1 \%$ das exportações
mundiais - apesar de haver abundância de talentos nesse continente.
Contudo, o cenário midiático mundial está em transformação e al-
guns países em desenvolvimento começam a impor-se como expor-
tadores de equipamentos culturais e de produtos de comunicação, e
até mesmo como produtores de conteúdos, contribuindo dessa forma
para os chamados os "contrafluxos" [...] (UNESCO, 2009).

Ferro (2010) nos vale novamente como referência, quando diz que o cinema é um produto da cultura que se conecta de forma bastante próxima com o discurso, tanto como veículo de construção de relatos históricos quanto por sua importância sociocultural para as sociedades. Ou seja, o cinema pode ser entendido como meio de construção e legitimação de um dado discurso, quer seja ele de conteúdo histórico, político, social, antropológico etc., que compõe o relato sobre a identidade coletiva ao mesmo tempo em que o torna público.

Os filmes são relatos ficcionais que provocam a reflexão sobre os deslocamentos reais e inspiraram este artigo. As trajetórias narradas nos três filmes podem ser vistas como registros históricos de um processo que se tornou crescente na esteira da globalização e que sempre teve destaque na vida do povo africano. Elas nos mostram visões de mundo que se constituem como desordenadas e híbridas e que se tornam uma marca da contemporaneidade.

A mobilidade humana, fenômeno intensificado nos tempos atuais, é encenada por migrantes, turistas, profissionais, exilados, refugiados, empresários, clandestinos, cientistas, artistas, desportistas, expressando-se também, como lembra Augé (2010, p.15), "na comunicação geral instantânea e na circulação dos produtos, das imagens e das informações”. Para o antropólogo, a desterritorialização e o individualismo seriam os valores básicos que explicam essa mobilidade em um mundo “cheio de 'abcessos de fixação' territoriais ou ideológicos" (AUGÉ, 2010, p.16). Nele se deslocam indivíduos, produtos e sentidos, estabelecendo um processo que corresponde, em grande medida, à ideologia do sistema da globalização e suas contradições. Contudo, nos explica Augé que a globalização liberal não é igualitária para facilitar to- 
das as formas de circulação, gerando paradoxos que permitem que os turistas viajem voluntariamente para lugares de onde saem migrantes, muitas vezes correndo risco de vida.

Para ele, a realidade contemporânea nos convida a pensar o conceito de fronteira como uma realidade a um só tempo renegada e reafirmada. As fronteiras não se desfazem, mas se reafirmam e se redesenham de uma forma enrijecida e que provoca exclusões. A história política do planeta parece questionar as fronteiras tradicionais.

As migrações dos países pobres para os países ricos constantemente assumem formas trágicas, e são os países liberais que erigem muros para se protegerem dos imigrantes clandestinos. Novas fronteiras se desenham, ou antes, novas barreiras se erguem seja entre países pobres e ricos, seja no interior dos países subdesenvolvidos ou países emergentes, entre os setores ricos, figurando na rede da globalização tecnológica e econômica e os outros (AUGÉ, 2010, p.21).

Assim como entendemos que as crescentes formas de mobilidades humanas repercutem nas percepções tradicionais de fronteiras culturais, podemos dizer também que provocam alteração na constituição moderna de identidade.

Conforme Hall (2003), a cultura e a identidade modernas não seguem mais modelos fechados. Para ele, no lugar antes idealmente ocupado pelo "ser" encontramos agora o "tornar-se" ou o "estar", condições que se referem a uma forma de identidade fluida, resultado de um processo de proliferação das diferenças e das combinações híbridas. A cultura global foi sendo transformada pelos movimentos diaspóricos de tal forma que cultura e identidade não se restringem mais a modelos homogêneos.

A análise de Canclini (2011) segue na mesma direção da feita por Hall quando afirma que:

Não é possível falar das identidades como se tratasse apenas de um conjunto de traços fixos, nem afirmá-las como a essência de uma etnia ou de uma nação. A história dos movimentos identitários revela uma série de operações de seleção de elementos de diferentes épocas articulados pelos grupos hegemônicos em um relato que lhes dá coerência, dramaticidade e eloquência (CANCLINI, 2011, p. XXIII). 
É nossa intenção aqui ressaltar as características das identidades híbridas (BHABHA, 2001) que provocam novos modos de pensar sobre identidade cultural, a partir das paisagens que se desenham por meio das narrativas sobre diferentes experiências de deslocamentos. O sujeito que deixa seu local de origem parece estar em posição privilegiada para questionar as visões de mundo totalizadoras ou que pretendem ser inteiras ou puras.

A análise dos três filmes nos sugere refletir sobre as representações que estes fazem da relação entre tradição e modernidade em um mundo em constante transformação, da concepção de território como uma "casa" primordial e fixa à qual se tenta permanecer conectado, mas para onde não é possível voltar, e do papel do Estado como provocador de muitos casos de desterritorialização na África, quer seja por sua ação direta ou por sua inércia política.

Estes temas, importantes no contexto moderno dos deslocamentos humanos, são também recorrentes nos filmes Casa de Lava, Nha Fala e Virgem Margarida. Uma vez que acreditamos que ocupam um lugar destacado no processo de construção de identidades de sujeitos deslocados, serão tomados como pontos centrais das nossas análises.

A abordagem metodológica adotada para o desenvolvimento da pesquisa utilizou-se dos apontamentos de autores que trataram das questões pertinentes ao tema em foco, a saber, as representações cinematográficas e a mobilidade humana. Esses conceitos serviram para orientar o estudo das obras de ficção Casa de Lava (1994), de Pedro Costa, Nha Fala (2002), de Flora Gomes, e Virgem Margarida (2012), de Licínio Azevedo. A perspectiva da análise de conteúdo foi utilizada, considerando-se o filme como um relato sobre o tema da mobilidade humana. Aplicada em sua vertente qualitativa, partiu de uma série de pressupostos, os quais, no exame de um texto ou filme, servem de suporte para captar seu sentido simbólico. Este sentido nem sempre é manifesto e o seu significado é plural, podendo ser interpretado a partir de diferentes perspectivas.

\section{CASA SEM SOMBRA NEM FRESCOR}

Em Casa de Lava, dirigido por Pedro Costa (1994), destacamos o percurso de Leão (interpretado por Isaach de Bankolé), um emigrante cabo-ver- 
diano em Portugal que é apresentado na tela como trabalhador da construção civil. Leão cai de um andaime da obra, entra em coma e o acidente leva-o de volta a Cabo Verde, acompanhado por Mariana (interpretada por Inês Medeiros), uma enfermeira portuguesa. Os dois são os personagens centrais na trama e passam por experiências que lhes afetam percepções já constituídas acerca das culturas das quais participam.

Trata-se do segundo filme do diretor português, após o Sangue (1989), no qual já se começa a configurar a concepção destacada pelo filósofo Rancière (2009) como central em seus trabalhos:

Os seus filmes têm aparentemente como objecto essencial uma situação que está no centro do que está em jogo, em termos políticos, no nosso presente: a sorte dos explorados, daqueles que vieram de longe, das antigas colónias africanas, para trabalhar nos estaleiros de construção portugueses, que perderam a família, a saúde, por vezes a vida nesses estaleiros; aqueles que se amontoaram ontem nos bairros de lata suburbanos antes de serem expulsos para habitações novas, mais claras, mais modernas, não necessariamente mais habitáveis (RANCIÈRE, 2009, p. 53).

Casa de Lava tem uma dimensão política densa, por abordar, como pano de fundo da história de Leão e Mariana, a repressão salazarista. As lentes de Pedro Costa representam Cabo Verde por imagens inóspitas de terra ressecada, como uma casa para a qual Leão é levado de volta e que recebe seu morador não com sombra e frescor, mas com lava quente de vulcão. O filme mostra também que ali está o Tarrafal, colônia penal inspirada nos campos de concentração nazistas, instalado naquele país em 1936 pelo regime salazarista para encarcerar seus opositores. Para o Cabo Verde iam os insurgentes; do Cabo Verde partiam os africanos em busca de melhores condições de vida na metrópole.

A mobilidade retratada no filme é protagonizada por explorados e desamparados, a exemplo de Leão e Mariana, e como Edith, que para lá se mudou para ficar próxima de seu companheiro mantido encarcerado no Tarrafal até a sua morte. Esses personagens deslocados e expostos aos desafios de tradução de uma nova realidade e cultura se resguardam em suas individualidades como forma de suportar uma existência complexa. 
Leão está em coma pela queda sofrida, mas nos parece razoável dizer que sua manifestação é de ausência de si mesmo e de uma casa, de um território, de práticas culturais em que pudesse se enxergar como um dos participantes. Nada mais é natural para Leão, nem a pretensa casa cabo-verdiana, nem Portugal, que lhe negou a existência e lhe concedeu a periferia e a exclusão.

A enfermeira Mariana, embora vinda da metrópole, também vive à margem da sociedade portuguesa por ser mulher e não pertencer à elite social, econômica e política. Como tal, parece achar natural afastar-se de si mesma e mergulhar nos cuidados a Leão e à população local. Contudo, ainda que em Portugal Mariana esteja revestida de elementos de exclusão, Cabo Verde carrega consigo a força de um Portugal colonialista. Sua coragem para proteger Leão ou para se livrar de uma tentativa de estupro, por exemplo, não advém exclusivamente de suas características pessoais, mas, em grande parte, por representar ali a figura do colonizador. Nesta condição, faz-se guarnecida de uma superioridade branca que lhe dá a distinção de uma perita que pode determinar na colônia atitudes de higiene, pode vacinar crianças ou dissuadir com seus argumentos irrefutáveis outros interessados em migrar para Portugal em busca de um futuro melhor.

Edith, mulher branca vinda de Portugal e igualmente deslocada de seu contexto cultural de origem, nos surge como uma mistura indecifrável de louca e bêbada. Seu comportamento, entretanto, pode ser a estratégia que encontrou para circular em Cabo Verde - local dos "desterros": o seu, de seu companheiro e de seu filho. Na interpretação de Rancière (2009), Edith se esqueceu da língua portuguesa para se encerrar na bebida e na língua crioula.

O pai e o irmão de Leão, por outro lado, representam o desejo de mobilidade como um ideal inacessível a muitos. Pensam em partir, em deixar a música que fazem para alegrar a noite da colônia em troca do exílio em Portugal, na busca por trabalho.

Os percursos descritos no filme, mais com sombras do que com luzes, nos alertam para a ideia de que as raízes culturais não são seguras nem fixas. Ao contrário, as mudanças e movimentos inerentes à dinâmica social levam as pessoas a terem que arquitetar para si rotas culturais itinerantes.

Merece destaque no filme a sua forma de narrar. Ao lado de imagens em movimento que irão contar as histórias teremos outras congeladas, de personagens, lugares e objetos da ilha que parecem nos apontar para outras 
versões de sua história. Essa pode ter sido uma tentativa do diretor de mostrar no plano estrutural os diferentes pontos de vista apresentados por aqueles que produzem deslocamentos em sentidos opostos.

As condições que levaram Leão para Portugal e o aparente descaso com que é recebido ao voltar para "casa” não são revelados por uma narrativa linear. É Mariana que vai tentar desvendar esse mistério ao longo da trama. Para isto, ela trava contato com outros moradores da Ilha que parecem colocados ali como peças isoladas. Entretanto, há uma trama de relações entre eles que não é sinalizada claramente para a visitante estrangeira.

Uma das razões para o clima desconfortável de sigilo que o filme apresenta pode ser o receio da população com relação ao regime opressor de Salazar. A menção ao Tarrafal anuncia a causa do distanciamento, da insegurança e do silêncio. Aqui, o expectador é introduzido por Pedro Costa a um contexto histórico e político que aponta o Estado como um ator desencadeador de tantos deslocamentos involuntários do povo de Portugal e de suas colônias africanas, sendo muitos deles forçados.

Mariana e Leão se diferenciam pela nacionalidade, pelo gênero, pela etnia e pelos lugares que ocupam na estrutura social, mas se aproximam pela experiência da exclusão, pelo deslocamento, pela desvinculação em relação à terra de origem e pelo desejo de uma vida melhor. Porém, Leão não encontrará acolhida em sua terra natal. Na condição de retornado a casa, espera-se que vá encontrar ali uma retomada de sentido de sua vida, a revelação de quem ele é, de onde é originário, a qual contexto pertence. Voltar para casa deveria ser o retorno a um lugar onde é bem-vindo, onde seria cuidado pelos seus e estaria entre aqueles que se parecem com ele. Essa casa, contudo, não se desenha em formas nítidas, e sim incompletas, obscuras e deixadas a um passado fragmentado e descontinuado com o presente.

Leão é um deslocado e este senso permanece mesmo com seu retorno ao território geográfico da Ilha. Ainda que as noções de nacionalidade, etnicidade ou raça configuram-se como esferas de pertencimento dos indivíduos a grupos pretensamente homogêneos, esses modelos não parecem ser mais suficientemente adequados diante das consequências da mobilidade humana e de suas diásporas. $\mathrm{O}$ modo como as pessoas deslocadas pensam seu lugar e sua terra dificilmente gera sentido direto de pertencimento. Outras possibili- 
dades identitárias surgem desse contexto, colocando os sujeitos na condição de in-between.

Podemos dizer que Leão experimenta uma dupla mobilidade: submetido a trabalho em condição análoga à do trabalho escravo em Portugal e como sujeito isolado e discriminado pela origem e pela raça no contexto colonial. Hall (2003) destaca que estas são duas formas ímpares de subordinação, mas ambas exigem do sujeito a capacidade de se adaptar infinitamente a culturas mais poderosas. Neste sentido, a mobilidade humana é um intenso laboratório cultural em que tentativas de sobrevivência são trabalhadas e experimentadas.

Para Hall (2003), a modernidade representa tanto a possibilidade de mobilidade quanto a falta de um destino, de uma chegada segura e definitiva: estamos todos sem rumo, somos parte de um processo que suscita sentimentos ambíguos de pertença e de deslocamento, memória e esquecimento. Sendo assim, Mariana, Edith, Leão, seu pai e seu irmão são indivíduos que encarnam a história de todos aqueles que precisam partir, descentrados não só com relação ao seu mundo de origem, mas de si mesmos.

As expectativas de uma vida melhor, da inserção na "modernidade" e da aquisição de um sentido para a vida dificilmente são alcançadas. Impelidos a se lançar no mundo, em geral, permanecem nos migrantes sentimento de identificação com a cultura de origem e a vontade de retorno a "casa". Contudo, como demonstram os personagens de Casa de Lava, a "casa" se transforma em um lugar mítico e para o qual não se regressa, mesmo quando voltam ao seu território geográfico de origem.

Mariana e Leão parecem estar na situação que Giddens (1990) denominou de insegurança ontológica, que provém da dissolução da tradição e implica a vivência de "vertigens" emocionais, a perda de confiança no conhecimento tradicional, a instabilidade da autoidentidade e da sociedade circundante.

O filme Casa de Lava nos permite perceber representações dos indivíduos deslocados, bem como o modo pelo qual tentam se construir como novos tipos de sujeitos. A trama dirigida por Pedro Costa, além de tratar dos impactos que os deslocamentos humanos trazem para subjetividade de seus participantes, indica as dificuldades interativas dos personagens envolvidos nos processos de mobilidade. 
Os Estudos Culturais problematizaram esses impactos nos contatos entre culturas das populações colonizadas e culturas dos países colonizadores, revelando significativas dificuldades na relação com a alteridade. No filme, a enfermeira Mariana, perdida e confusa, tenta se envolver com os habitantes da aldeia, mas não os compreende.

Mariana e Leão, igualmente desencaixados de suas tradições, de suas comunidades e de si mesmos, mostram que a modernidade é uma "promessa que não se cumpre minimamente" (DOMINGUES, 2004, p.155). Apesar disso, permanece o esforço para a construção de novas identidades numa sociedade movida pela insatisfação das expectativas que ela própria criou, e que cotidianamente promove a incerteza sobre os modos de satisfazê-las.

\section{VITA, SONHO, IMAGINÁRIO, OUSADIA}

O filme Nha Fala (2002) recebe de seu realizador Flora Gomes o título em crioulo da Guiné-Bissau, que pode ser traduzido por "a minha fala” ou "a minha voz". O cineasta, pioneiro do cinema guineense, estudou em Cuba e na França, tornando-se um diretor premiado e uma referência do cinema africano. O filme pode ser definido como uma comédia musical e tem roteiro de Flora Gomes e Franck Moisnard, músicas compostas por uma lenda das artes africanas, o músico Manu Dibango, e coreografias de Clara Andermatt e Max-Laure Bourjolly.

Nha Fala foi filmado em Cabo Verde e na França - a Guiné-Bissau, a partir de 1999, entrou em fortes conflitos civis. É falado em crioulo e em francês e as cenas se passam também em ambiente africano e francês. A alternância de cenários e de línguas é um indicador importante da mobilidade contemporânea dos povos africanos, representados pela trajetória da personagem central.

A história contada no filme é protagonizada pela jovem Vita (Fatou N’Daye), que recebe uma bolsa para estudar em Paris, tendo, portanto, que deixar Guiné-Bissau, a família, os amigos e o namorado Yano, com o qual vivia uma relação já desgastada. A primeira parte do musical, passada na África, mostra a jovem terminando seu relacionamento com Yano e se despe- 
dindo de amigos e familiares. Essa despedida é feita alegremente, mas alguma tensão se forma quando Vita se depara finalmente com sua mãe, que vai alertá-la sobre uma maldição tradicional que estabelece que as mulheres da sua família não podem jamais cantar. A morte é a punição para o descumprimento dessa profecia.

Essa cena é emblemática para a análise que queremos fazer do filme, porque coloca a personagem central, bem como os espectadores, diante da tradição que se confronta com a modernidade. No caso, a tradição familiar de Vita perante os prováveis valores modernos que vai encontrar na sua nova vida na Paris cosmopolita.

De acordo com Giddens (1997), podemos dizer que Vita está prestes a passar por uma experiência frequente na alta modernidade: o seu desencaixe das relações sociais que estabeleceu na África para viver novas experiências na França. Os desencaixes e reencaixes promovem uma nova postura dos indivíduos, obrigados a lidar com perigos e riscos de dimensões supralocais; ao mesmo tempo, criam novas oportunidades emancipatórias, o que dá a esse processo um caráter duplo.

Os múltiplos modos de mobilidade humana que levam os povos de suas terras de origem para outros lugares e outros significados simbólicos não fazem necessariamente com que haja o abandono das tradições, porém elas não são mantidas "puras". Os conteúdos tradicionais são remodelados continuamente pelos que partem, o que pode acarretar um retorno conflituoso a "casa". Muitos retornados sentem falta dos ritmos de vida que experimentaram, às vezes mais cosmopolitas do que o que conheciam anteriormente, ou passam a não reconhecer sua terra e a se sentirem deslocados nela. As posições simbólicas de pais e filhos, conforme ressalta Augé (2010), podem se diferenciar ao ponto de aqueles parecerem estrangeiros aos olhos destes. Os filhos migrados detêm experiências radicalmente discrepantes das de seus pais, mesmo quando os pais são também migrados, mas vivem em comunidades diaspóricas que lhes possibilitam manter, no cotidiano, um alto índice de práticas tradicionais.

Hervieu-Léger (1999) diz que as crenças e as tradições passam por um processo de reorganização nos deslocamentos contemporâneos, movido pela insaciabilidade do sujeito diante das expectativas suscitadas pela sociedade contemporânea e pela incerteza da busca por satisfação. A mobilidade gera o 
reconhecimento da diversidade e da heterogeneidade, bem como uma concepção de identidade "que vive com e através, não a despeito, da diferença; por hibridização. Identidades de diáspora são as que estão constantemente produzindo-se e reproduzindo-se novas, através da transformação e da diferença" (HALL, 2003, p.75).

Vita, antes da partida, parece desconhecer as novas experiências que lhe aguardam. Ela promete à mãe que vai observar a tradição familiar e seguir a recomendação para nunca cantar. Em Paris, todavia, passa a namorar o músico Pierre. O convívio com o rapaz e com seus amigos desperta nela a vontade de cantar. A jovem, não sem relutar, supera a tradição familiar, as recomendações maternas, e canta. Como é dona de uma bela voz, acaba por gravar um CD, recebido com comemoração por seus novos amigos franceses. Ela, contudo, não ignora sua tradição nem a morte prometida, mas realiza essa morte no campo simbólico. Volta à Guiné-Bissau para organizar seu funeral, cumprindo simbolicamente a profecia e associando tradição e modernidade num ato de ousadia.

Ousar é ideia que perpassa a narrativa do filme, que tem nítido caráter afirmativo do modo de vida africano alegre, sensual, descontraído, colorido e fraterno. Seguindo a linha do embate entre tradição e mudança cultural, o filme se inicia com a imagem de crianças encenando um cortejo fúnebre para enterrar o papagaio da escola que havia morrido e que só sabia falar uma única palavra: silêncio. Uma vez morta a ordem de silêncio, segue-se uma cena na qual Vita passa pela rua e há mulheres cantando para ela uma música cheia de recomendações para sua nova vida: "O que fazer quando hesitamos antes de agir? - Você tem que ousar" ("Bo tem di ousa"). É, provavelmente, a ousadia de Vita que a leva a partir para uma terra distante em busca de seu desejo de conhecimento, mesmo sem aprovação do namorado.

Também com ousadia, Vita celebra alegremente sua partida para um outro mundo com cantores do coro da igreja, desafiando um padre sisudo. Depois, comemora com os amigos na carpintaria. A despedida de Vita é um acontecimento positivo, recebido com festejos que são entrecortados pelo assédio do namorado preterido, a única voz dissonante do musical.

No adeus entre Vita e sua avó temos uma das cenas nas quais Flora Gomes concilia tradição e modernidade. A avó parece aprovar a decisão da neta e, numa atitude despojada, pede que lhe mande de Paris uma combinação 
cor-de-rosa bonita e decotada para a frente. A seguir, cerimoniosamente, a senhora tira o colar de seu pescoço e o coloca em Vita. Esse objeto permanecerá com ela nas cenas em Paris, nas quais vemos que trocou seu vestuário leve, com estampas coloridas e que valorizam sua sensualidade, por roupas europeias.

Enquanto Vita anda pelas ruas se despedindo das pessoas são mostradas cenas tradicionais do lugar em que vive, da sua gente e de seus costumes. Ela encontra um grupo de crianças que canta uma trova popular: "Papagaio louro do bico dourado/ Toma esta carta para levar para o namorado”. $\mathrm{Na}$ cena seguinte, há uma fila de pessoas enviando por intermédio de Vita objetos e cartas para pessoas queridas que estão fora da África. Os destinos são mencionados: "Paris, Londres, Lisboa, Portugal, Europa, América, China, Estocolmo, Roma, Boston, Lucerna”. Nesta cena há um muro com uma faixa sugestiva, na qual se lê: "Viaje conosco de todo mundo para todo mundo", tendo abaixo a pintura de um avião.

Após participar do velório do senhor Sonho, homem longevo que morre no dia de sua partida, Vita sai pela mesma estrada em que vai o cortejo fúnebre, mas seu percurso é de um novo começo, em busca de um outro sonho que está vivo: seu sonho de estudar e de usufruir de tudo o que isso pode lhe trazer. Morre o velho "sonho" da tradição, marcado pelo "silêncio", que também morreu, e Vita viaja a Paris, um marco da modernidade, introduzido no filme pela imagem previsível da Torre Eiffel.

Em Paris, atores brancos cantam em francês, usando roupas de inverno, em contraste com as roupas africanas mostradas na primeira parte do filme. Vita agora tem amigos e namorado francês, fala francês fluentemente e surge de casaco amarelo e cachecol, cabelos soltos sem as tranças de seu penteado africano, mas mantém no pescoço o colar dado pela avó. A transformação no figurino usado pela protagonista denota, portanto, mudança e permanência. Ela é também a única pessoa de pele negra no grupo que se forma ao seu redor, mas não se pode dizer que se encontra entre eles em situação de subordinação devido à sua origem ou cor da pele.

Possivelmente, a mobilidade de Vita que se dá mediante a obtenção de uma bolsa de estudos é retratada aqui como um novo tipo de relação entre Europa e África, na qual a motivação para o deslocamento de jovens africanos não os coloca necessariamente em uma situação colonial, subalterna 
e de exclusão. Permite-lhes viver entre a tradição de sua referência cultural e as práticas modernas de um mundo globalizado. Isso não quer dizer que a inserção do estrangeiro africano na Europa e na França, especificamente, como é o caso do filme, aconteça na contemporaneidade sem qualquer tipo de resistência, preconceito ou conflito.

Flora Gomes retrata uma "África que ri” e, para isso, apresenta no seu filme Nha Fala uma africana que se desloca ancorada em apoios institucionalizados, da organização que lhe confere a bolsa de estudos no exterior e da rede de familiares e de amigos que festejam sua nova aventura em terra estrangeira como algo positivo e desejável.

Tal não significa que a narrativa sobre uma África que canta e dança desconheça as formas de preconceitos destinados aos estrangeiros em muitos países ricos, em especial aos negros. No filme, o preconceito é caracterizado por um velho branco, provavelmente francês, personagem que repete a todo tempo que não gosta de pretos. Ele é o único idoso entre jovens, o que confere uma imagem caricatural à intolerância, ou seja, o diálogo entre as culturas é jovem, o preconceito é velho. No final do filme, o velho francês chega à África, terra dos pretos que ele despreza, juntamente com os jovens e se atraca com uma bela mulher negra numa dança divertida. Esta cena desconstrói a pretensão daquele personagem de ser um guardião do nacionalismo francês. O diretor não desconhece o preconceito, mas nos leva a rir dele.

O encontro de Vita com os pais de Pierre, seu namorado, se dá numa situação ambígua, que mescla cordialidade com a expressão de certo conformismo diante da escolha do filho por uma namorada negra. Os pais deixam claro para Vita que a boa recepção não significa que ela não seja vista como alguém diferente deles. Destaca-se a fala um tanto resignada da mãe de Pierre de que não espera ter netos tão claros quanto ela.

A globalização colocou os pais de Pierre diante de uma futura nora de outra etnia, de outra cor de pele e outra cultura. Eles são também donos de um restaurante no qual trabalham imigrantes de variadas nacionalidades. $\mathrm{Na}$ cena que se passa no estabelecimento, há uma dança ritmada por tambores que preenche o ambiente francês com ritmo africano. Os bailarinos, que representam empregados do restaurante, anunciam ao longo da dança sua origem: uma portuguesa, um espanhol, um argelino, um senegalês, uma francesa etc. 
Os pais de Pierre, na condição de comerciantes típicos em Paris, parecem estar familiarizados com as situações que, segundo Canclini (2011), intensificaram as interculturalidades migratórias, econômicas e midiáticas, levando tanto às confrontações quanto aos diálogos.

A decisão de Vita de cantar, seguindo o seu desejo e atendendo à insistência do namorado, vem após uma cena de sexo, tendo ao fundo os emblemáticos telhados de Paris. Ela é Vita, vida, sonho, imaginário, ousadia. Seu êxito é o êxito da vida africana, cheia de histórias de superação, pobreza, estatísticas trágicas, mas que não foram capazes de matar os sonhos, o riso e a solidariedade.

Vita grava seu CD, que recebe o título de La Peur (o medo), mas, neste momento, decide que precisa lidar com a tradicional profecia familiar, e não meramente ignorá-la. Ao decidir voltar à casa da família para organizar seu funeral, a personagem se encontra diante do desafio de explicar a tradição ao namorado estrangeiro e a modernidade à sua mãe. Ela representa uma África contemporânea que conjuga, no presente, o passado e o futuro, e pretende equalizar a busca dos sonhos arregimentados pelo contato com uma vida moderna e cosmopolita.

Volta, então, ao continente negro com Pierre para organizar seu funeral cenográfico, que é apresentado no mais típico estilo de comédia, realizando a profecia como uma alegoria simbólica. Vita dá atenção à tradição familiar ao mesmo tempo em que se livra dela. O preparo do funeral tem ares carnavalescos, com cenografia colorida e com efeitos como o caixão cor-de-rosa, em forma de borboleta que bate asas. Essa cena registra uma concepção de África que ri e que faz comédia do presente e do futuro.

Com a chegada dos amigos franceses na África para participarem do ritual, Flora Gomes promove o encontro ficcional entre a cultura europeia e africana de maneira festiva e aparentemente igualitária, reunindo na tela do cinema os dois mundos pelos quais Vita e tantos outros africanos transitaram: uma encenação ficcional da constituição de sujeitos que partilham de culturas híbridas. No sentido dado por Canclini (2011, p. XIX), a hibridação pode ajudar a dar conta de formas particulares de conflito geradas na interculturalidade recente.

Augé (2010, p. 57-58) aponta que "um dos dramas de nossa época é que muitos indivíduos, devido a fatos como a colonização, a globalização, o êxodo 
rural, guerras, fomes e a migração, foram despossuídos de seus saberes tradicionais, sem ter acesso, no entanto, aos modos de conhecimento modernos". Não importa o que Vita foi estudar em Paris, a bolsa de estudos faz dela portadora de um poder fundamental para lidar com a situação híbrida de respeito aos saberes tradicionais, ao mesmo tempo em que utiliza a razão para conduzir sua vida. A tradição, mantendo-se como um conjunto de referências que ainda afeta os padrões interativos de Vita, foi exposta e confrontada com a racionalidade moderna. Permanece, mas passou por mudanças quantitativas, ocupando um lugar muito mais simbólico do que prático.

\section{DESTERRADOS NA PRÓPRIA CASA}

No filme Virgem Margarida (2012), dirigido por Licínio Azevedo, o deslocamento registrado não é transnacional, como nos casos anteriormente discutidos. A película, em primeiro lugar, retrata fronteiras culturais internas e, em segundo lugar, contribui para evidenciar o papel do Estado nos casos de deslocamentos na África.

A história de Margarida (Sumeia Maculuve), moça virgem do campo, analfabeta, de 16 anos, foi inspirada em fatos reais e se passa em Moçambique pós-colonial, imediatamente às lutas pela libertação da então colônia portuguesa. O país se torna independente em 1975, passando a ser dirigido, sem eleições, pela Frente de Libertação de Moçambique (Frelimo). A Frelimo assumiu o papel de Estado intervencionista e teve todo tipo de dificuldades para manter o controle político e a economia operando. À libertação de Moçambique de Portugal seguiu-se um longo período de destruição, causada pela guerra civil entre a Frelimo e a Resistência Nacional Moçambicana (Renamo), que só cessou 16 anos depois, em 1992.

O antropólogo Peter Fry, que conheceu o Moçambique dos anos 1960, voltou àquele país em 1989 e fez o seguinte relato sobre a herança trágica da guerra:

Naquela época, Moçambique estava mergulhado numa guerra violenta entre o governo da Frelimo e a Renamo [...]. Dezenas de milhares 
de pessoas morreram na guerra, e centenas de milhares morreram de fome e das doenças causadas por ela. Aproximadamente quatro milhões, de uma população total de quinze milhões, estavam refugiados em países vizinhos, e muitos mais, os "internamente deslocados", procuraram asilos nas cidades (FRY, 2005, p. 69).

Fry (2005) destaca que a guerra civil moçambicana gerou "novas categorias de pessoas", referindo-se aos refugiados, deslocados internos e às crianças traumatizadas pelas atrocidades que presenciaram. Margarida é uma das vítimas dessas atrocidades, sendo forçada a se deslocar pela imposição de um Estado autoritário. Ela está noiva, vai do campo a Maputo (capital e maior cidade de Moçambique) acompanhada de uma tia para comprar seu enxoval de casamento e, na cidade, é confundida com prostitutas que estão sendo levadas pelos soldados revolucionários para um centro de reeducação. Tais centros, projeto de base marxista que já havia sido experimentado na China de Mao Tse Tung, tiveram como objetivo formar o novo homem moçambicano, socialista, purificado dos valores coloniais combatidos.

Os centros de reeducação socialista de Moçambique recebiam aqueles considerados traidores do regime, bem como desempregados, criminosos, vagabundos e prostitutas, que eram enviados, sem qualquer triagem, das cidades ao campo no norte do país. A justificativa para esse deslocamento forçado era de que seriam libertos da mentalidade colonialista e transformados em novas forças a serviço da revolução.

Explica Fry (2000) que os princípios coloniais portugueses foram transformados na independência em uma nova ordem marxista-leninista, com base em uma leitura rasa do marxismo. Os slogans como "abaixo o feudalismo", "abaixo o colonialismo", "abaixo o obscurantismo" e "a luta continua", dentre outros, marcaram, conforme relata o autor, o fim do passado colonial e tradicional para o nascimento do "novo homem" socialista. As escolas, de acordo com sua narrativa, estavam adornadas com fotografias de Marx, Engels, Lenin e Samora Machel, acompanhadas de frases didáticas que sugerem a passagem de Moçambique de uma organização social tribal para a chamada "linguagem universalista do marxismo". Na prática, o autoritarismo capitalista comandado pelos portugueses era semelhante ao autoritarismo socialista.

Margarida e as centenas de mulheres prostitutas deveriam passar pela educação revolucionária marxista, o que implicava a reprodução de palavras 
de ordem, vestir-se como os camponeses revolucionários, na valorização do trabalho árduo como forma essencial da redenção e disciplina impecável. Nos centros de reeducação, os controladores assumiram a posição de guardiões de um ideal que, em geral, foi sendo substituído pela violência, pela tortura e pelo desmando. O programa foi extinto por Samora Machel em 1989.

$\mathrm{Na}$ análise de Colaço (2001),

Contrariando as propostas revolucionárias para a recuperação da dignidade africana, da sua história e da sua cultura, os tecnocratas moçambicanos de hoje (políticos e intelectuais revolucionários) seguiram o caminho iniciado pelos teóricos do colonialismo português no qual as possibilidades de construção de uma sociedade moderna exigiam o rompimento com a visão de mundo das sociedades tradicionais africanas. A transformação dessas sociedades significou a recusa de uma existência social própria das comunidades tradicionais, abrindo espaço a conflitos que levaram ao colapso tanto do colonialismo português quanto do regime socialista (COLAÇO, 2001, p.107).

No filme Virgem Margarida são movidas as prostitutas urbanas para o campo e é deslocada Margarida para a convivência com as mulheres com experiências muito distintas da dela. A cena inicial do filme mostra uma grande poça enlameada na qual surge o reflexo de um caminhão, que está ocupado por militantes revolucionários carregando faixas com palavras de ordem. A principal delas, sobre a qual a câmera se detém, anuncia “a luta continua”.

Numa região típica de meretrício, os militantes revolucionários armados buscam as mulheres nas ruas e nos bordéis, forçando-as a entrarem no caminhão onde já está Margarida. Elas usam roupas curtas, coloridas e decotadas, as quais, mais tarde, serão trocadas por uniforme escuro que lhes esconde as formas do corpo. Paulatinamente, vão tentando descobrir o que as espera. Na primeira noite a caminho do norte do país, ainda há risos e piadas, que serão substituídos nos dias seguintes pela revolta de umas e pelo conformismo de outras.

Margarida pede a uma das mulheres que escreva em um lenço o nome das cidades pelas quais passa, em direção ao norte de Moçambique, com a intenção de mostrar ao noivo por onde andou. O bordado de Margarida nos remete a Penélope à espera de Ulisses e tem o papel simbólico de tentar fixá- 
-la a uma realidade, a um universo cultural familiar que se esfuma repentinamente.

As "mulheres da vida" são entregues às "mulheres revolucionárias", comandadas por Maria João (Hermelinda Cimela), que abriu mão do convívio com a família e com o namorado em nome da revolução. Encontra-se há tanto tempo longe de suas referências originais a ponto de não haver mais vestígios de que tenha tido uma história própria. Todo o seu discurso é uma sequência de clichês. "Camarada" é o tratamento dado a todos e suas roupas são como alegorias militares. Embora sonhe em voltar para uma casa primordial para se casar e ser mãe, na prática é impelida a trabalhar para a resistência e para uma transformação de Moçambique em um país que não se sabe ao certo qual seria.

A disciplina, ela repete, vai fazer das putas novas mulheres. Assim são reiteradas formações e instruções militares sob sol escaldante, alimentação regrada, acomodações duras e trabalho com a enxada para abrir latrinas e caminhos por meio das mãos de mulheres urbanas acostumadas a fazer outros tipos de trabalho com o corpo. Ser puta para elas não têm qualquer relação com o colonialismo, mas para a polícia revolucionária é uma atitude reacionária, expressão do obscurantismo que deve ser punida com castigos físicos.

Ainda que a força de repressão empurre essas mulheres para práticas culturais camponesas, não consegue superar estranhamentos. Elas desconhecem o ambiente do campo e as plantas, e uma delas morre ao comer uma fruta venenosa. Margarida vem do campo, porém para ela também representa uma situação de estranhamento. A moça virgem e inexperiente não tem a menor familiaridade com o universo das demais mulheres: por que foi levada junto com elas?

Ao se constatar a virgindade de Margarida, os revolucionários concordam em retirá-la do centro de reeducação, o que acaba não acontecendo porque ela é estuprada pelos "novos homens revolucionários" e volta para junto do grupo. O estupro de Margarida levanta a questão sobre quem é colonizador e quem é libertador. A revolta que se segue atinge Maria João, que decide abandonar o Centro e libertar as mulheres. O cortejo sai pela trilha aberta no mato. Vai se compondo de mulheres uniformizadas, mas agora cada uma delas carrega, dobradas junto ao peito, suas roupas coloridas, sapatos de salto 
alto, marcas de uma cultura para qual esperam voltar, como vestígio da resistência ao deslocamento imposto.

Para Margarida, ter perdido a virgindade impossibilita a sua volta. Não há mais um lugar no qual se encaixe na sua tradição e ela prefere, então, comer do fruto venenoso a se expor à família e ao noivo. Assim, segue a trilha que a manterá para sempre à margem de um mundo perdido.

A personagem central do filme é vítima das condições contemporâneas de vida que, segundo Giddens (1997), obrigam os sujeitos à administração dos riscos e oportunidades criadas a partir de várias influências, muitas vezes desconectadas de um local específico, dando origem a novas formas de relacionamento social. Cultura e identidade, contudo, são noções complexas que se tornam problemáticas diante da combinação do analfabetismo e do repertório reduzido de Margarida para se adaptar a outros valores e modelos culturais.

\section{CONSIDERAÇÕES FINAIS}

Mesmo compreendendo que a experiência da modernidade se expandiu pelo mundo de forma desigual e é combinada com culturas diversas (DOMINGUES, 2004), de modo geral pode-se dizer que é notável o fato de que as tradições perderam quase que completamente sua capacidade de moldar comportamentos e de ter credibilidade frente a indivíduos com disposição para utilizar a razão como referência na condução de sua vida.

Como parece ter ocorrido na esfera ficcional com Leão, Mariana, Edith, Vita, Margarida e as prostitutas moçambicanas, tal acontece também nas vidas reais. As identidades se tornam, por razões diversas, desvinculadas de tempos, lugares, histórias e tradições específicas, e se compõem com outros arranjos híbridos. A "casa" em um mundo marcado pelos deslocamentos e pela desterritorialização das pessoas e das relações pode continuar a ser construída como um ideal, mas se torna um ponto inatingível no horizonte, enquanto as identidades, muitas vezes tidas como estabelecidas e estáveis, estão naufragando diante da proliferação das diferenças e das combinações híbridas. 


\section{REFERÊNCIAS BIBLIOGRÁFICAS}

1. APPIAH, Kwame Anthony. Na casa de meu pai; a África na filosofia da cultura. Rio de Janeiro: Contraponto, 1997.

2. AUGÉ, Marc. Por uma antropologia da mobilidade. São Paulo/Maceió: Unesp/ UFAL, 2010.

3. BAMBA, Mahomed. Introdução. In: MELEIRO, Alessandra (Org.). Cinema no mundo: África. V. 1. São Paulo: Escritora Escrituras, 2007.

4. BAUMAN, Zygmunt. Globalização: as consequências humanas. Rio de Janeiro: Jorge Zahar Editor, 1999.

5. BAUMAN, Zygmunt. O mal-estar da pós-modernidade. Rio de Janeiro: Jorge Zahar Editor, 1998.

6. BHABHA, Homi K. O local da cultura. Belo Horizonte: Editora UFMG, 2001.

7. CASA de Lava. Direção: Pedro Costa. Portugal, França e Alemanha, 1994. 110 min, son.,color.

8. CANCLINI, Néstor Garcia. Culturas híbridas. São Paulo: EDUSP, 2011.

9. COHEN, Robin. Global diásporas. London: UCL Press, 1997.

10. COLAÇO, João Carlos. Trabalho como política em Moçambique: período colonial ao regime socialista. In: FRY, Peter (Org.). Moçambique. Ensaios. Rio de Janeiro: UFRJ, 2001.

11. DOMINGUES, José Maurício. Interpretando a modernidade. Rio de Janeiro: FGV, 2002.

12. FERRO, Marc. História das colonizações. São Paulo: Companhia das Letras, 1996.

13. FRY, Peter. A persistência da raça. Ensaios antropológicos sobre o Brasil e a África Austral. Rio de Janeiro: Civilização Brasileira, 2005.

14. FRY, Peter. Cultures of difference: the aftermath of Portuguese and British colonial policies in Southern Africa. Disponível em: http://onlinelibrary.wiley. com/doi/10.1111/j.1469-8676.2000.tb00125.x/abstract._Acesso em: 31 ago. 2015.

15. GIDDENS, Anthony. A vida em uma sociedade pós-tradicional. In: BECK, U.; GIDDENS, A.; LASH, S. Modernização reflexiva. São Paulo: Unesp, 1997.

16. HALL, Stuart. Da diáspora: identidades e mediações culturais. Belo Horizonte: Editora UFMG, 2003.

17. HALL, Stuart. Identidade cultural e diáspora. Revista do Patrimônio Histórico e Artístico Nacional, Brasília, n.24, p.68-75, 1996. 
18. HERVIEU-LÉGER, Danièle. Le pèlerin et le converti. Paris: Flammarion, 1999.

19. MCLEOD, John. Beginning postcolonialism. Manchester: Manchester University Press, 2000.

20. MOSCOVICI, S. A representação social da psicanálise. Rio de Janeiro: Zahar, 1978.

21. NHA Fala. Direção: Flora Gomes. Portugal, França e Luxemburgo, 2002. 35 mm (85 min), son.,color.

22. RANCIÈRE, Jacques. Política de Pedro Costa. Disponível em:_https://pt.scribd. com/doc/38218932/Politica-de-Pedro-Costa-Jacques-Ranciere\#download. Acesso em: 21 set. 2015.

23. UNESCO. Segundo relatório mundial da UNESCO. Investir na diversidade cultural e no diálogo intercultural. Paris: UNESCO, 2009.

24. VENÂNCIO, José Carlos. O fato africano. Elementos para uma sociologia da África. Recife: Fundação Joaquim Nabuco, 2009.

25. VIRGEM Margarida. Direção: Licínio Azevedo. França, Portugal e Moçambique, 2012. $95 \mathrm{~min}$, son.,color.

Recebido em 19 de maio de 2019

Avaliador A: 14 de julho de 2019

Avaliador B: 14 de agosto de 2019

Aceito em 14 de agosto de 2019 